\title{
Invited review: Genomic selection for small ruminants in developed countries: how applicable for the rest of the world?
}

\author{
R. Mrode ${ }^{1,2 \dagger}$, G. M. Tarekegn ${ }^{3 a}$, J. M. Mwacharo ${ }^{4}$ and A. Djikeng ${ }^{5 b}$ \\ Biosciences, International Livestock Research Institute (ILRI), PO Box 30197, Nairobi 00100, Kenya; ${ }^{2}$ Scotland Rural College, Peter Wilson Building, Kings Buildings, \\ West Mains Road, Edinburgh, EH9 3JG, UK; ${ }^{3}$ Department of Animal Production and Technology, Biotechnology Research Institute, Bahir Dar University, PO Box 79, \\ Bahir Dar, Ethiopia; ${ }^{4}$ Small Ruminant Genetics and Genomics Group, International Centre for Agricultural Research in the Dry Areas (ICARDA), PO Box 5689, Addis \\ Ababa, Ethiopia; ${ }^{5}$ Biosciences Eastern and Central Africa-International Livestock Research Institute (BecA-ILRI Hub), PO Box 30197, Nairobi 00100, Kenya
}

(Received 3 April 2017; Accepted 7 December 2017; First published online 18 January 2018)

Improved management and use of estimated breeding values in breeding programmes, have resulted in rapid genetic progress for small ruminants (SR) in Europe and other developed countries. The development of single nucleotide polymorphisms chips opened opportunities for genomic selection (GS) in SR in these countries. Initially focused on production traits (growth and milk), GS has been extended to functional traits (reproductive performance, disease resistance and meat quality). The GS systems have been characterized by smaller reference populations compared with those of dairy cattle and consisting mostly of cross- or multi-breed populations. Molecular information has resulted in gains in accuracy of between 0.05 and 0.27 and proved useful in parentage verification and the identification of QTLs for economically important traits. Except for a few established breeds with some degree of infrastructure, the basic building blocks to support conventional breeding programmes in small holder systems are lacking in most developing countries. In these systems, molecular data could offer quick wins in undertaking parentage verification and genetic evaluations using $G$ matrix, and determination of breed composition. The development of next-generation molecular tools has prompted investigations on genome-wide signatures of selection for mainly adaptive and reproduction traits in SR in developing countries. Here, the relevance of the developments and application of GS and other molecular tools in developed countries to developing countries context is examined. Worth noting is that in the latter, the application of GS in SR will not be a 'one-size fits all' scenario. For breeds with some degree of conventional genetic improvement, classical GS may be feasible. In small holder systems, where production is key, community-based breeding programmes can provide the framework to implement GS. However, in fragile growth systems, for example those found in marginal environments, innovative GS to maximize adaptive diversity will be required. A cost-benefit analysis should accompany any strategy of implementing GS in these systems.

Keywords: small ruminants, genomic selection, signatures of selection, QTL

\section{Implications}

The basic building blocks for conventional breeding programmes for small ruminants (SR) in most developing countries are lacking. However, genomic data offers unique opportunities to circumvent some of the limitations through parent verification, genetic evaluations using the $G$ matrix and understanding the molecular basis of adaptation through genome-wide association studies (GWAS). The application of genomic selection (GS) may, however, need to be tailored

\footnotetext{
${ }^{\dagger}$ E-mail: R.Mrode@cgiar.org

a Present address: Swedish University of Agricultural Sciences, Uppsala, Sweden. ${ }^{b}$ Present address: Centre for Tropical Livestock Genetics and Health, The Roslin Institute \& Royal (Dick) School of Veterinary Studies, Easter Bush, Midlothian, EH25 9RG, Scotland.
}

to the conditions of specific production environments, for example small holder $v$. pastoral systems.

\section{Introduction: role of small ruminants in developing countries}

Globally, the largest number of SR occur in Asia $(49.70 \%)$, followed by Africa $(27.90 \%)$ and then Europe $(8.70 \%)$, summing up to $86.3 \%$ of world total (FAOSTAT, 2013). SR meat and milk production represents $4.8 \%$ and $3.4 \%$ of the total meat and milk produced, respectively, in the world. These percentages are comparatively smaller in developed $(3.0 \%$ and $1.6 \%)$ than in developing countries $(6.2 \%$ and $6.1 \%$, respectively), emphasizing the significant role of SR in 
developing countries. In addition, SR offer a wide range of products in developing countries including skins, manure and (mo)hair/pelts, and play critical socio-cultural roles in many communities (Kosgey and Okeyo, 2007). They also represent a large repository of genetic diversity that is well adapted to diverse agro-ecologies and are critical to the poor in marginal areas where arable agriculture is too risky or rearing cattle is not feasible (Devendra, 2002). The production systems in Europe are based mostly on improved management and well defined and structured breeding programmes, while about $70 \%$ to $85 \%$ of SR products are derived from the small holder and pastoral systems in developing countries. The small holder and pastoral systems are low-input, characterized by small flock sizes, lack of infrastructure and animals of unimproved genotypes. Most often, higher productivity is not usually the goal trait, especially when production risks are high (Amer et al., 1998).

Current advances in molecular biology has resulted in the discovery of unprecedented levels of genomic variation as a result of sequencing efforts, and consequently, the development of various single nucleotide polymorphisms (SNPs) chips for genotyping purposes. The reduction in genotyping costs and advances in statistical methods (Meuwissen et al., 2001), has made it possible to incorporate molecular information in SR breeding programmes in many European and developed countries to accelerate the rate of genetic progress in production and somewhat difficult to measure traits. The question that arises therefore is how applicable are the molecular based methods including GS to the rest of the world especially in developing countries. This review presents an overview of GS and other molecular-based methods in the improvement of SR in the developed countries and then examines their potential and feasibility for application in the developing countries.

\section{Systems for conventional breeding programmes in developed countries for small ruminants}

Fundamental to the implementation of GS is the existence of an already established system of genetic evaluation based on efficient performance and pedigree recording. In an attempt to increase the efficiency of the productivity of SR, many developed countries have implemented breeding programmes based on estimated breeding values (EBVs) using performance and pedigree data. The maturity in mixed model approaches (Henderson, 1949) has resulted in more accurate estimates of EBVs accelerating the rate of genetic progress and the profitability of SR enterprises. For instance, in the New Zealand sheep industry there was an $83 \%$ increase in $\mathrm{kg}$ of lamb produced per ewe and up to $28 \%$ overall in carcass weight from 1990 to 2012 (Beef and Lamb New Zealand, 2012). Examples of established well-structured genetic evaluation systems that underpin such genetic improvement programmes for SR include Basco database for sheep and beef improvement in the United Kingdom (http://www. basco.org/sheep), French genetics for cattle, sheep and goats (http://en.france-genetique-elevage.org), Sheep Improvement
Limited in New Zealand (https://www.sil.co.nz/), and Canadian dairy goat breeding programme (http://www.goatgenetics.ca).

These improvement programmes for SR are mostly focussed on meat, wool and dairy production, and more recently, breeding objectives have also included other functional traits such as reproductive performance and disease resistance/tolerance but little emphasis on carcass and meat quality traits (Pannier et al., 2014). While rapid rates of genetic progress for growth-related or milk traits have been achieved in these programmes, a relatively lower rate of progress is possible for traits that are measured later in the life of females, such as reproductive ability, breeding seasonality and longevity (Rupp et al., 2016) due to the longer generation interval or, in carcass composition traits which are recorded on the relatives of selection candidates and require animals to be sacrificed (Daetwyler et al., 2012).

\section{Overview of genomic selection and molecular approaches in developed countries for small ruminants}

The advent of GS and GWAS opened new opportunities for breeding programmes in SR especially for traits measured late in life and carcass traits. These opportunities in GS and GWAS resulted from the development of next-generation sequencing technologies which allowed de novo sequencing of sheep and goat genomes; and the subsequent development of dense SNP Chips such as the Illumina Goat SNP50 BeadChip (Tosser-Klopp et al., 2014), the Ovine SNP50 BeadChip (Kijas et al., 2012) and recently the Ovine $600 \mathrm{~K}$ SNP BeadChip (Anderson et al., 2014). Recently, a low-density panel with 16301 SNPs for sheep has been developed by the International Sheep Genomics Consortium (Larroque et al., 2017)

The basic principle undergirding GS is that SNPs are assumed to be at LD with QTLs in the genome. Therefore the use of SNPs as markers enables all QTLs in the genome to be identified through the mapping of chromosome segments defined by adjacent SNPs. The implementation of GS usually involves estimating the SNP effects in a reference population which consists of individuals with phenotypic records and genotypes. This is then followed by prediction of genomic EBV for selection candidates with no phenotypes of their own (Meuwissen et al., 2001). Details of the design of actual GS in SR have been described by Rupp et al. (2016).

Genomic predictions and selection in SR for developed countries have either been successfully implemented or their feasibility demonstrated on a number of standard production traits such as wool, growth traits, muscle and fat depth in New Zealand (Auvray et al., 2014), Australia (Daetwyler et al., 2010), in dairy sheep and goats in France (Carillier et al., 2014) and in dairy goats in the United Kingdom (Mucha et al., 2015). Recently, GS in SR has been applied to breed for disease resistance such as parasite and fly-strike resistance (Pickering et al., 2015) and facial eczema (Phua et al., 2014). There is also on-going work on genomic prediction for traits such as feeding efficiency and methane emissions (Pickering et al., 2015). 
The characteristics of these genomic prediction systems for SR include reference populations of smaller sizes compared with dairy cattle and consisting of mostly cross-breeds or multi-breed populations. In summary, the reference populations ranged from 1900 for Western Pyrenees dairy sheep breeds to 8000 multi-breed Australian meat sheep (Rupp et al., 2016). The gains in accuracy provided by molecular information are rather lower (range from 0.05 to 0.27 ) given the small size of the reference populations. Details of accuracies from studies on genomic predictions for SR are outlined by Rupp et al. (2016).

Genomics has offered the opportunity to identify and include major genes (QTLs) associated with reproductive, disease or production traits. A comprehensive list of such QTLs is outlined by Rupp et al. (2016) including some of the genes that are already being used in breeding programmes, such as PrP, FecL or the $\alpha$-s1 casein (French goats), to preselect candidates for progeny testing. In recent times, genomic approaches have been used to identify novel mutations influencing functional traits. For instance, Demars et al. (2013) used GWAS and identified new mutations associated with prolificacy in sheep. The discovery of actual genes and causative mutations underlying prolificacy has been a subject of intense investigation in sheep in developed countries. The findings have paved the way for the development of commercial DNA assays/tests/Kits, which require no parental information, to identify breeding stock with high prolificacy. Such tests have been developed for the Inverdale $\left(F e c X^{\prime}\right)$ and Boorola $\left(F e c B^{B}\right)$ mutations and are commercially available in Australian and New Zealand sheep industry where rams are tested to breed heterozygous progenies (Davis, 2005; Walkden-Brown et al., 2009).

In addition to genomic prediction, the use of genotypic information plays an important role in parentage verification and assignment in SR in developed countries. In breeding schemes for $S R$, parentage identification is an issue due to the limited use of artificial insemination and use of natural mating, involving most likely multiple sires, in extensive systems. In these natural mating schemes parentage is either unknown or incomplete and the use of genetic markers, initially microsatellites and currently SNPS, have proved useful to detect misidentified and unknown parents. For details of the various SNP chips available for parentage verification, the reader should see Rupp et al. (2016). In addition to parentage identification, genotypic information is useful for assessing genetic diversity and structure of local sheep and goat breeds. Genotypic data gives more accurate estimates of relationship between individuals than pedigree records and therefore offers better opportunities for more accurate estimation of co-ancestry, mate assignment and inbreeding coefficients (Rupp et al. (2016).

\section{Summary of some breed improvement programmes for SR in developing countries}

The existence of well-established conventional genetic evaluation and selection programmes provide the necessary platform for the implementation of GS. In most developing countries, genetic improvement programmes for SR are scarce. The major constraints include lack of performance and pedigree information and the non-existence of institutional frameworks and infrastructure including inadequate farmers' organizations at the village level to effectively participate in breeding schemes (Kosgey and Okeyo, 2007). Most of the production occurs in small holder systems which are characterized by small flock sizes, uncontrolled mating and lack of pedigree recording and therefore the difficulty of defining adequate contemporary groups. However in a few countries, breeding improvement programmes for SR have been implemented, and these are briefly summarized.

\section{Kenya dual purpose goat development Project}

The Kenya dual purpose goat development (KDPG) breeding programme was started in 1980 as part of the Small-Ruminant Collaborative Research Support Program (SR-CRSP) funded by the United States Agency for International Development and implemented by Kenya's Ministry of Livestock Development. The overall objective was to develop a synthetic breed of goat that combined the adaptability of the indigenous East African and Galla goats and the growth and milk producing abilities of theToggenburg and Anglo-Nubian breeds. Ojango et al. (2010) provides a detailed summary of the breeding programme for the KDGP goat.

The foundation flock consisted of 250 Small East African (E) goats from across Kenya and 200 Galla (G) goats sourced from the dry Northeastern province of Kenya. With no production data available, these animals were selected based on phenotypic characteristics such as large and sound udders and teats and the local 'milk line' claim, a distinctive black stripe along the back of some Galla goats. These were initially mated to different Toggenburg and Anglo-Nubian bucks, and later insemination was done using semen from the United States. A nucleus breed was established at Ol-Magogo Estate of the National Animal Research Centre, Naivasha (Mwandotto et al., 1992), where productivity and pedigree recording was undertaken by enumerators. An interdisciplinary farming systems approach was used (0jango et al., 2010) to develop and test the breeding programme (Semenye et al., 1989). Kenya Dual Purpose Goat Development development occurred at Ol-Magogo Estate, while breeding animals were provided to a station in Maseno Western Kenya, which was closer to the target farmers. On-farm testing of the KDPG was carried out by small holder farmers from contrasting socio-cultural and environmental backgrounds. Each farmer received two to four breeding does and breeding bucks were rotated amongst groups of farmers. The project developed the KDPG breed. On-farm the KDGP reached their milk peak after 1 week of kidding, producing $600 \mathrm{ml} /$ day for household use while On-station, it reached peak milk production, 3 weeks after kidding, producing $1500 \mathrm{ml} /$ day (Onim, 1992). In on-farm trials, the KDPG produced on average $0.49 \mathrm{l} /$ day with a range of between 0.05 and $2.70 \mathrm{l} / \mathrm{day}$ (Semenye et al.,1989). The local does at the station peaked after 6 weeks of kidding, producing a daily milk production of $400 \mathrm{ml}(0 \mathrm{nim}, 1992)$. At the 
peak of its operation, a breeding flock of the KDPG established at Ol-Magogo Estate stood at 1800 animals. By 2005, the population was $<400$ animals (Bett, 2005) due to the termination of the breeding and farmer development programme for the KDPG and the SR-CRSP project (Ojango et al., 2010). Within the last decade, there has been renewed interest in the KDPG and a re-evaluation of its breeding strategies (Ojango et al., 2010).

\section{Community-based breeding programmes for sheep and goats in Ethiopia}

The International Center for Agricultural Research in the Dry Areas (ICARDA), the International Livestock Research Institute (ILRI), and Austria's University of Natural Resources and Life Sciences, in partnership with the Ethiopian National Agricultural Research System, have designed and implemented community-based SR breeding programmes in Ethiopia since 2009 (Haile et al., 2014). Similar communitybased breeding programmes (CBBP) for indigenous goats of Ethiopia and Cameroon were also implemented by Biosciences Eastern and Central Africa (BecA-ILRI) Hub in 2013 for three production systems (arid agro-pastoral, semi-arid agro-pastoral and highland mixed crop-livestock systems; Woldu et al., 2016). The CBBP are designed to take into account farmers' needs, views, decisions and active participation, from inception to implementation, and their success is based upon proper consideration of farmers' breeding objectives, infrastructure, participation and ownership (Wurzinger et al., 2011). The goal of CBBPs is to improve the productivity and income of small-scale resourcepoor SR producers by providing access to improved animals that respond to improved feeding and management, and facilitating the targeting of specific market opportunities.

There is a governmental rural organization associated with each of the sites where the CBBPs are in operation. Local enumerators are recruited for each site to assist the research system in animal identification and recording. Indigenous knowledge of the community is considered at each phase of the project. For example, the community decides how rams are managed and how they are shared and used. The aim is to get community members to work as a team in selecting, managing and using rams. Two stages of selection are applied, initial screening when first sales of young rams occur (4 to 6 months) and final selection for admission to breeding at 12 months of age. Selection at the first stage is based on 6 months weight and ewe lambing interval. Yearling weights and body conformation are considered in the final selection.

There are currently 23 CBBPs across Ethiopia operating in 15 sheep and eight goat sites. Each CBBP involves an average of 60 households/site and 600 flocks with an average flock size of 10 animals. To automate the recording and ensure real-time archiving, an online database Data Recording and Management System (DREMS) was developed (jointly by EMBRAPPA-Brazil and ICARDA). In DREMS, data can be keyed-in offline from a mobile devise (tablet, computer, mobile phone, etc.) and updated once online.
The information is archived in a server maintained at EMBRAPPA-Brazil.

\section{Goat improvement programmes in South Africa}

The South Africa Boer Goat Breeders' Association was formed in 1959 but development of the Boer goat as a meat breed dates back to 1918. The National Performance Testing Scheme however, commenced in 1970. Two other dairy breeds were further developed from the Boer goat. These were the White Savanna, which was initiated in 1957 and a breed society formed in 1993 and the Kalahari Red which started in 1990. Genetic improvement of these dairy goats is still based on the convectional hand and eye method (Casey and Webb, 2010) and the South African Studbook Association and Milch Goat Breeders Society handles records of goat breeds and milk production. Genetic progress is rather slow, but substantial amount of genetic improvement has been realized in the past especially in the meat goat sector.

Animal recording in the mohair producing Angora goats, was piloted in 1983, with the approval of the Angora Stud Breeders' Society. This was followed by the closure of the Angora herd book in 1984 and in 1999 animal recording for the Angora goat was operationalized within the National Small Stock Information Scheme of South Africa. The breeding programme for the Angora goat in the South African mohair production systems was designed on the basis of the study by Snyman and Olivier (1999). The initial selection index was based on fibre diameter, fleece weight and BW. Intensive selection for increased mohair production from the early 1970s until 1990 with no selection directed towards weaning weight, resulted in unthrifty animals with an inability to survive sub-optimal conditions (Visser and Van Marle Köster, 2014). The selection strategy was re-evaluated in 2002 and it was concluded that selection for decreased fibre diameter, while maintaining or increasing BW and fleece weight seems optimum for the breed. In addition, molecular research has been undertaken with a view of including molecular information in the breeding programme. A microsatellite marker panel consisting of 14 markers has been developed and utilized for parentage verification in the breed (Visser et al., 2011b). Similarly 18 QTLs for mohair traits including fleece weight, fibre diameter and other related traits have been identified on 13 chromosomes (Visser et al., 2011a).

\section{Goat and sheep improvement programmes in India}

A goat improvement programme involving 34 villages was initiated by the Nimbkar Agricultural Research Institute in 1991 in South-Central Maharashtra of India with the aim of improving goat productivity through crossbreeding (Nimbkar, 1999). A total of 34 villages within a $15 \mathrm{~km}$ radius of Phaltan town in south-central Maharashtra province formed the target area for the crossbreeding project. It involved 13 Sirohi bucks selected on their individual growth rates and their mothers' milk yields, 10 Alpine $\times$ Sirohi and 10 Toggenburg $\times$ Sirohi bucks which were bought and introduced into the project. The improved bucks were placed in the villages for 
crossbreeding of local goats and no efforts were made for the dissemination of cross-bred males and females generated in the course of the project. The project was supported by veterinarians, who visited each project village once a week. The project ran for 4 years but collapsed due to lack of funds. The author concluded that it provided a framework for an effective breeding programme when individual units are small and spread out over a large area.

Similar crossbreeding programme to improve the fecundity of Deccani sheep of Maharashtra was summarized by Nimbkar et al. (2002), which involved the introgression of the Booroola gene from the Indian Garole breed into the Deccani and a composite breed.

\section{The relevance of developments in genomic seletion and other molecular approaches in developed countries for the rest of the world}

\section{Parentage and breed composition verification}

One the possible quick wins from the developments in molecular-based approaches and the utilization of genotypic information in SR breeding in developing countries includes parent verification and breed composition of cross-bred animals. The rather extensive systems for the management of SR in small holder systems and the lack of infrastructure to capture pedigree information has resulted in the inability to undertake genetic evaluation in these systems or control breeding. Therefore the availability of genotypic information will reduce the need for accurate pedigree recording as genomic relationships can be computed to undertake genetic evaluation, estimate inbreeding and undertake parentage verification. However, most of the initial work on parentage verification so far in these systems are based on microsatellites. A microsatellite marker panel consisting of 14 markers has been developed and utilized for parentage verification in the Angora Breed (Visser et al., 2011b). Similarly, genotypic data can easily be used through admixture analysis to determine breed composition in cases where crossbreeding and uncontrolled mating is practiced and therefore be utilized to match appropriate genotypes to the relevant management systems. However, the utilization of genomic information in the small holder systems for SR is rather slow compared with dairy cattle where genetic predictions have been undertaken using the G matrix computed using SNP data (Brown et al., 2016). In the ILRI-led Africa Dairy Genetic Gains project, a small chip of about 400 SNPs for parentage verification and breed composition for dairy cattle is being developed (Gibson and Mwai, personal communication).

\section{Detection of signatures of selection and use of molecular markers in breeding in small ruminants}

In contrast to SR in Europe and the developed world, SR in the developing countries remain nondescript in genotype and phenotype, the consequence of modest anthropological selection. The analysis of microsatellites and recently SNP genotype and full genome sequence data in SR in the developing world has revealed high genetic diversity that mirrors their extensive phenotypic diversity as well as the diversity in their production environments and historical migration and admixture patterns. Analysis of signatures of selection have revealed candidate regions in the genome harbouring genes with demonstrated roles in phenotypic variation including fat and thin tail, horn size and polledness, body morphology, limbs and skeleton development, pigmentation, etc. (Fariello et al., 2014). In a GWAS study, Gholizadeh et al. (2015) identified significant association between a single SNP located in the SYNE1 gene on chromosome 8 with yearling weight in Baluchi sheep found across southwest Pakistan, eastern Iran and southern Afghanistan. Using different approaches, multiple selection sweep regions spanning several candidate genes relating to various traits (immunity, nervous and endocrine system development, metabolism, thermo-regulation, reproduction, etc.), metabolic pathways and biological processes driving adaptation to local environments have been revealed in Black, Draa and Northern goat populations of Morocco (Benjelloun et al., 2015), various breeds of sheep in Africa, Asia and South West Asia (Fariello et al., 2014), Barki sheep and goats from Egypt (Kim et al., 2016) and the indigenous goats in South Africa (Mdladla, 2016). Kim et al. (2016) further identified one selection sweep region that was common to both the Barki sheep and goats from Egypt providing possible evidence for a common region under selection in a common environment in the two species. Gouveia et al. (2017) identified genomic regions under selection which overlap genes influencing traits associated with ecological adaptation, phenotypic and production differences amongst three Brazilian locally adapted sheep breeds (Brazilian Creole, Morada Nova and Santa Ines). It is worth noting that in most of these studies, the identified selection sweeps and their genomic distribution differ between populations/breeds but reflect, to a large extent, the outcomes of local adaptation. This suggests that artificial selection seems to play a minor role in driving genome evolution in SR in developing countries and natural selection tends to favour adaptive diversity.

The characterization of the indigenous goats in Ethiopia and Cameroon populations using mitochondrial DNA and $50 \mathrm{k}$ SNP chip array was also undertaken by Getinet (2016). A high level of genetic diversity but weak genetic structure was found among the goat populations in both countries. However, the Keffa goat, reared in highly tsetse infested area, and Abergelle goat, also known with its drought tolerance, were found to have relatively maintained their pure genetic background. Coding regions of the kisspeptein gene were found in Gondar and Woyto-Guji goats in Ethiopia and the genotypes detected were associated with multiple births in these goat populations (Getinet et al., 2017).

With the exception of Brazil and possibly India, the use of molecular markers in SR breeding lags behind in most developing countries. In Brazil use of molecular markers in animal breeding has concentrated on two fronts: those controlled by many genes of small effect (meat and milk production, Lôboa et al., 2010), on which classical breeding is based, or traits controlled by few genes of large effect. 
The latter have several examples in sheep such as those linked to prolificacy (booroola, inverdale or galway), muscle mass (callipyge) or resistance/susceptibility to scrapie (PNRP). Castro et al. (2006) identified a mutation linked to prolificacy specific to naturalized Brazilian breeds.

\section{Potential for the application of genomic selection in developing countries}

The production system for SR in developing countries can be considered to occur along a trajectory in terms of management systems with one end of the spectrum consisting of breeds operating mostly on a commercial scale basis, having some degree of genetic improvement and investment on infrastructure while on the end is the fragile growth systems, mostly the pastoralists/nomads in arid environments. (Smith et al., 2013). Opportunities for the application of GS will therefore not be 'one size fits all' but very much dependent on the intersection of the spectrum being considered. Commencing at one end of the spectrum where production is at a commercial scale, with some organizational structures (breed societies) and some investments in IT infrastructure, such as the Boer, Savanna, Kalahari and Angora goat breeds in South Africa, huge opportunities exist for GS. In this production system, the emphasis is mostly on productivity traits with less weight put on adaptive traits. The existing structures such as the progeny testing scheme (Snyman and Olivier, 1999), the availability of performance and pedigree records imply that classic GS (GBLUP or Single step) could be applied. Potential improvements in this setting is to translate to the use of digital systems (mobile phones or tablets) to collect performance data (Mrode et al., 2016), as it avoids or reduces the huge organizational infrastructure and high costs associated with recording systems. Additional benefit from genomics in this setting is the reduction for the need to accurately record pedigrees as genomic relationships can be computed and parentage verification implemented using SNP genotype data.

In the middle of the spectrum are the small holder systems which account for most (70\% to $80 \%$ ) of the outputs from SR. While the emphasis here is still on production traits, adaptive traits play very significant role, therefore innovative GS will be needed that ensures adequate balance between production and adaptive traits. However, community-based breeding programmes, such as the FARM-Africa Meru and Tharaka-Nithi Districts dairy goat and animal healthcare project in Kenya among other initiatives, seem to be the best approaches for implementing GS as the rotational use of selected males provide opportunity to select superior males using SNP genotype data, given that performance recording pooled from several flocks by digital means can be initiated or is already in place. The within breed selection implemented in these projects ensures that adaptability of local breeds can be monitored overtime and mating can be controlled. However several scenarios need to be evaluated considering different genotyping strategies and the economic aspects to determine the best approach for implementing GS in this setting. In addition, production and adaptive traits can be optimized in the context of CBBP via gene/genome/ haplotype block editing (Jenko et al., 2015) utilizing the genomic regions identified in combination with GS in developing appropriate synthetic breeds.

At the other end of the spectrum is the fragile growth systems consisting mostly of very extensive systems of the pastoralists and nomads in arid and semi-arid environments, where adaptive traits are key and the main goal will be to maximize adaptive diversity. The implementation of GS in this system possess major challenges. However, the widespread usage of the mobile phone in these systems for other purposes, such as money transfers, imply that digital data capture and recording could be possible with adequate farmer training. The use of communal grazing lands, watering points and other services could innovatively be used to introduce recording of basic performance data, initiate sampling for genotyping of animals and also introduce the use of superior males. The initial use of such data could be the application of GWAS and investigating signatures of selection to identify genomic regions associated with various aspects of adaptability (disease and drought for instance). As more data accumulates, genomic data will allow for a better understanding of genetic diversity in the fragile growth sector and how to select for it: for instance, the use of weighted GBLUP or Bayesian methods to optimize various aspects of adaptability. In the long term, usage of gene editing in addition to GS to increase and optimize the frequency of favourable alleles associated with different aspects of adaptability (Jenko et al., 2015) could be a possibility.

\section{Economic aspects of genomic selection in developing countries}

Given the significant role that SR play in the livelihood of farmers, the implementation of GS in the various management systems described especially the low-input small holder system and the fragile growth sectors should be accompanied by a cost-benefit analysis. The bottom line is that the introduction of GS should financially be beneficial to farmers and produce animals that are able to fulfil the other sociocultural roles played by SR in the community. The relatively high economic efficiency of GS in the dairy cattle is derived mostly from the large reduction in generation interval (König et al., 2008). In SR, the reduction in generation interval is not as large (Larroque et al., 2017) and the relatively higher cost of genotyping limits the cost-effectiveness of GS. Shumbusho et al. (2016) found that GS alone was not more beneficial in a French meat sheep breed compared with classical selection except when compared with some early measured phenotypes. However, the introduction of the low-density chip (16 k) for sheep increases the prospects of higher economic returns from GS. Larroque et al. (2017) demonstrated very high accuracy of imputation of the $16 \mathrm{k}$ chip to the $50 \mathrm{k}$ chip and concluded that it increases the cost-effectiveness of GS for French sheep breeds. Before implementing GS, some aspects to consider include product management and marketing issues that may accompany improved productivity and 
the prevailing socio-economic status of farmers, and flock structures and dynamics within the small holder system. However, cost can be reduced by sharing facilities such as databases or analytic platforms which may already be in existence for other livestock species such as cattle. The availability of the LD chip for sheep increases the prospect of long-term GS in SR in developing countries.

\section{Conclusions}

Unique genotypes of several goat and sheep breeds found in developing countries and especially in Africa present a good opportunity for understanding genetic diversity, structure and adaptation. The availability of molecular tools and approaches have enabled the understanding of the genetic basis for this diversity and adaptation, initially through the use of microsatellites and more recently SNP genotype and full genome sequence data. This information is foundational in terms of its incorporation in future breeding programmes for SR in developing countries. In the long term, the use of gene/haplotype editing and other emerging breeding strategies could play a role in incorporating these into breeding programmes for increased productivity.

The basic building blocks for conventional breeding are lacking in most of the small holder systems in developing countries apart from a few of the established breeds with some degree of supporting infrastructure. Genotypic data offers quick wins in terms of parentage verification, breed composition determination (admixture) and genetic evaluation using the $\mathrm{G}$ matrix.

Genomic selection in SR in developing countries will not be a scenario of 'one-size fits all' but it will depend on the type of production system. Classic GS is feasible in breeds with some degree of conventional genetic improvement already in place. The CBBP provides a good framework for the implementation of GS in small holder systems and innovative GS will be needed in fragile growth systems where adaptation is an important trait. Identifying regions of the genome associated with various aspects of adaptability and maximizing diversity of adaptation in animals reared will be essential. Adequate cost-benefit analysis should be part of any strategy adopted in implementing GS in these production systems.

\section{Acknowledgements}

None.

\section{Declaration of interest \\ None.}

\section{Ethics Statement}

None.

\author{
Software and data repository resources \\ None.
}

\section{References}

Amer PR, Mpofu N and Bondoc 0 1998. Definition of breeding objectives for sustainable production systems. In Proceedings of the Sixth World Congress on Genetics Applied to Livestock Production, 11 to 16 January 1998, Armidale, NSW, Australia, pp. 97-104.

Anderson R, McEwan J, Brauning R, Kijas J, Dalrymple J, Worley K, Daetwyler H, Van Stijn T, Clarke S, Baird H and Khan A 2014. Development of a high density (600K) Illumina ovine SNP chip and its use to fine map the yellow fat locus. Retrieved 28 March 2017 from https://pag.confex.com/pag/xxii/webprogram/ Paper10725.html

Auvray B, McEwan J, Newman SA, Lee M and Dodds K 2014. Genomic prediction of breeding values in the New Zealand sheep industry using a 50K SNP chip. Journal of Animal Science 92, 4375-4389.

Beef and Lamb New Zealand 2012. Domestic trends and measuring progress against the Red Meat Sector Strategy. Presentation to the Red Meat Sector Conference, 16 July 2012, Queestown. Retrieved 28 March 2017 from http:// www.mia.co.nz/docs/mia_conference/2012/Rob\%20Davidson.pdf

Benjelloun B, Alberto FJ, Streeter I, Boyer F, Coissac E, Stucki S, BenBati M, Ibnelbachyr $M$, Chentouf $M$, Bechchari A, Leempoel K, Alberti A, Engelen $S$, Chikhi A, Clarke L, Flicek P, Joost S, Taberlet $P$ and Pompanon F, NetGen Consortium 2015. Characterizing neutral genomic diversity and selection signatures in indigenous populations of Moroccan goats (Capra hircus) using WGS data. Frontiers in Genetics 6, 107.

Bett CR 2005. Developing breeding strategies for the Kenya dual purpose goat. MSc thesis, Animal Sciences, Egerton University, Kenya.

Brown A, Ojango J, Gibson J, Coffey M, Okeyo M and Mrode R 2016. Genomic selection in a crossbred cattle population using data from the dairy genetics project for East Africa. Journal of Dairy Science 99, 7308-7312.

Carillier C, Larroque H and Robert-Granié C 2014. Comparison of joint versus purebred genomic evaluation in the French multi-breed dairy goat population. Genetics Selection Evolution 46, 67.

Casey NH and Webb EC 2010. Managing goat production for meat quality. Small Ruminant Research 89, 218-224.

Castro EA, Lopez IMR and Lim A 2006. Characterization of a new SNP in the growth and differentiation factor 9 (GDF-9) gene, specific for the Brazilian Santa Inês sheep. Proceedings of the 8th World Congress on Genetics Applied to Livestock, Production, 13 to 18 August 2006, Belo Horizontal, Brazil, pp. 22-25.

Daetwyler HD, Pong-Wong R, Villanueva B and Woolliams JA 2010. The impact of genetic architecture on genome-wide evaluation methods. Genetics 185, 1021-1031.

Daetwyler HD, Swan AA, van der Werf JH and Hayes BJ 2012. Accuracy of pedigree and genomic predictions of carcass and novel meat quality traits in multi-breed sheep data assessed by cross-validation. Genetics Selection, Evolution 44, 33.

Davis GH 2005. Major genes affecting ovulation rate in sheep. Genetics Selection Evolution 37 (suppl. 1), S11-S23.

Demars J, Fabre S, Sarry J, Rossetti R, Gilbert R, Persani L, Tosser-Klopp G, Mulsant P, Nowak Z, Drobik W, Martyniuk E and Bodin L 2013. Genome-wide association studies identify two novel BMP15 mutations responsible for an atypical hyperprolificacy phenotype in sheep. PLoS Genetics 9, e1003482.

Devendra C 2002. Potential productivity from small ruminants and contribution to improved livelihoods in developing countries. (ed. AMV Batista, SBP Barbosa, MVF do Santos and LMC Ferrira), pp. 246-269. Proceedings of the Thirty Ninth Reuniao Anual, Sociedade Brasilia de Zootechnia. 29 July to 1 August 2002. Recife, Brazil, Secretaria Executiva, Sociedade Brasileira de Zootecnia, Brasilia, Brazil.

FAOSTAT 2013. FAO statistical yearbook 2913. World food and agriculture. Retrieved on 28 October 2017 from http://www.fao.org/docrep/018/i3107e/ i3107e.PDF.

Fariello M-I, Servin B, Tosser-Klopp G, Rupp R and Moreno C, ISGC, San Cristobal M and Boitard S 2014. Selection signatures in worldwide sheep populations. PLoS One 9, e103813.

Getinet M 2016. Molecular characterization of Ethiopian indigenous goat populations: genetic diversity, demographic dynamics and kisspeptin gene polymorphism. PhD dissertation. Addis Ababa University, Addis Ababa, Ethiopia.

Getinet M, Kassahun T, Tadelle D, Mwai O, Djikeng A, Osama S, Alayu K and Solomon A 2017. Analysis of Kisspeptin (KISS1) gene and its association with litter size in goats. African Journal of Biotechnology 16, 1254-1264. 
Gholizadeh M, Rahimi-Mianji G and Nejati-Javaremi A 2015. Genomewide association study of body weight traits in Baluchi sheep. Journal of Genetics 94 143-146.

Gouveia JJS, Paiva SR, McManus CM, Caetano AR, Kijas JW, Faco O, Azevedo HC Araujo AM, Souza CJH, Yamagishi MEB, Carneiro PLS, Lobo RNB, Oliveira SMP and Silva MVGB 2017. Genome-wide search for signatures of selection in three major Brazilian locally adapted sheep breeds. Livestock Science 197, 36-45.

Haile A, Dessie T and Rischkowsky B 2014. Performance of indigenous sheep breeds managed under community based breeding programs in the highlands of Ethiopia: preliminary results. ICARDA, Addis Ababa.

Henderson CR 1949. Estimation of changes in herd environment. Journal of Dairy Science 32,709 (Abstract)

Jenko J, Gorjanc G, Cleveland MA, Varshney KR, Whitelaw BA, Woolliams JA and Hickey JM 2015. Potential of promotion of alleles by genome editing toimprove quantitative traits in livestock breeding programs. Genetics Selection Evolution 47, 55

Kijas JW, Lenstra JA, Hayes B, Boitard S, Porto Neto LR and San Cristobal M 2012. Genome-wide analysis of the world's sheep breeds reveals high levels of historic mixture and strong recent selection. PLoS Biology 10, e100125.

Kim E-S, Elbeltagy AR, Aboul-Naga AM, Rischkowsky B, Sayre B, Mwacharo JM and Rothschild MF 2016. Multiple genomic signatures of selection in goats and sheep indigenous to a hot arid environment. Heredity 116, 255-264.

König S, Simianer H and Willam A 2008. Economic evaluation of genomic breeding programs. Journal Dairy Science 92, 382-391.

Kosgey IS and Okeyo AM 2007. Genetic improvement of small ruminants in low input, smallholder technical and infrastructural issues. Small Ruminant Research 70, 76-88.

Larroque $\mathrm{H}$, Chassier M, Saintilan R and Astruc JM 2017. Imputation accuracy from a low density SNP panel in 5 dairy sheep breeds in France. In Book of Abstracts of the 68th Annual Meeting of the European Federation of Animal Science, Tallinn, pp. 151.

Lôboa RNB, Facóa O, Lôbob AMBO and Villela LCV 2010. Brazilian goat breeding programs. Small Ruminant Research 89, 149-154.

Mdladla K 2016. Landscape genomic approach to investigate genetic adaptation in South African indigenous goat populations. PhD thesis, University of KwaZulu Natal, Pietermaritzburg, South Africa, 220pp.

Meuwissen TH, Hayes BJ and Goddard ME 2001. Prediction of total genetic valueusing genome-wide dense marker maps. Genetics 157, 1819-1829.

Mrode R, Han J, Mwacharo JA and De Koning DJ 2016. Novels tools to informanimal breeding programs. International Livestock Research Institute, Brief No. 14. Retrieved on 30 October 2017 from https://livestockfish.cgiar.org/ 2017/01/27//fbrief14/

Mucha S, Mrode R, MacLaren-Lee I, Coffey M and Conington J 2015. Estimation of genomic breeding values for milk yield in UK dairy goats. Journal Dairy Science 98, 8201-8208.

Mwandotto BAJ, Ruvuna F, Taylor JF and Cartwright TC 1992. Breeding strategies for genetic improvement. Retrieved on 5 January 2018 from http://hdl. handle.net/10568/70845.

Nimbkar C 1999. A village goat cross-breeding project in Maharashtra, India. Workshop for developing breeding strategies for lower input animal production environments. Bella, Italy, September, 1999. ICAR Technical Series 3, 435-443.

Nimbkar C, Ghalsasi PM, Walkden-Brown SW and Kahn LP 2002. Breeding program for the genetic improvement of the Deccani sheep of Maharashtra, India. 7th World Congress on Genetics Applied to Livestock Production, 19 to 23 August 2002, Montpellier, France. Session 25. Developing sustainable breeding strategies in medium- to low-input systems Communication No. 25-11.

Ojango JMK, Okeyo AM and Rege JEO 2010. The Kenya dual purpose goat development project. Animal Genetics Training Resource (AGTR), An ILRI/SLU
Project. Retrieved on 30 October 2017 from http://agtr.ilri.cgiar.org/agtrweb/ index.php?option=com_content\&view=article\&id 203\&Itemid=240

Onim JFM 1992. Dual-purpose goat research in western Kenya. In Future of Livestock industries in East and southern Africa. Proceedings of a workshop held at Kadoma Ranch Hotel, Zimbabwe (20 to 23 July 1992. (ed. JA Kategile and S Mubi), p. 229. International Livestock Centre for Africa, Addis Ababa, Ethiopia.

Pannier L, Pethick DW, Geesink GH, Ball AJ, Jacob RH and Gardner GE 2014. Intramuscular fat in the longissimus muscle is reduced in lambs from sires selected for leanness. Meat Science 96, 1068-1075.

Phua S, Hyndman D, Baird H, Auvray B, McEwan J, Lee M and Dodds K 2014. Towards genomic selection for facial eczema disease tolerance in the New Zealand sheep industry. Animal Genetics 45, 559-564.

Pickering NK, Oddy VH, Basarab J, Cammack K, Hayes B, Hegarty RS, Lassen J, McEwan JC, Miller S, Pinares-Patiño CS and Haas de Y 2015. Invited review: genetic possibilities to reduce enteric methane emissions from ruminants. Animal 9, 1431-1440.

Rupp R, Mucha S, Larroque H, McEwan J and Conington J 2016. Genomic application in sheep and goat breeding. Animal Frontiers 61 , 39-44.

Semenye PP, Onim JFM, Conelly WT and Fitzhugh HA 1989. On-farm evaluation of dual-purpose goat production systems in Kenya. Journal of Animal Science 67, 3096-3102.

Shumbusho F, Raoul J, Astruc JM, Palhiere I, Lemarié S, Fugeray-Scarbel A and Elsen JM 2016. Economic evaluation of genomic selection in small ruminants: a sheep meat breeding program. Animal 10, 1033-1041.

Smith JW, Tarawali S, Grace D and Sones K 2013. Feeding the world in 2050: trade-offs, synergies and tough choices for the livestock sector. Tropical Grasslands - Forrajes Tropicales 1, 125-136.

Snyman MA and Olivier JJ 1999. Repeatability and heritability of objective and subjective fleece traits and body weight in South African Angora goats. Small Ruminant Research 34, 103-109.

Tosser-Klopp G, Bardou P, Bouchez O, Cabau C, Crooijmans R, Dong $Y$, Donnadieu-Tonon C, Eggen A, Heuven HC, Jamli S, Jiken AJ, Klopp $C_{\text {, }}$ Lawley CT, McEwan J, Martin P, Moreno CR, Mulsant P, Nabihoudine I, Pailhoux E, Palhiere I, Rupp R, Sarry J, Sayre BL, Tircazes A, Jun W, Wang W and Zhang W 2014. Design and characterization of a 52 K SNP chip for goats. PLoS One 9, e86227.

Visser C and Van Marle Köster E 2014. Strategies for the genetic improvement of South African Angora goats. Small Ruminant Research 121, 89-95.

Visser C, Crooijmans RPMA, Bovenhuis H and Van Marle-Köster E 2011a. QTL for mohair traits in South African Angora goats. Small Ruminant Research 100, 8-14.

Visser C, Van Marle-Köster E and Friedrich H 2011b. Parentage verification of South African Angora goats, using microsatellite markers. South Africa Journal of Animal Science 41, 250-255.

Walkden-Brown SW, van der Werf JHJ, Nimbkar C and Gupta VS (eds) 2009. Use of the $\mathrm{FecB}$ (Booroola) gene in sheep-breeding programs. Proceedings of Helen Newton Turner Memorial International Workshop Pune, Maharashtra, India, 10 to 12 November 2008. ACIAR Proceedings No. 133. Australian Centre for International Agricultural Research: Canberra.

Woldu T, Markemann A, Reiber C, Mutha PC and Zárate AV 2016. Optimizing contributions of goat farming to household economic success and food security in three production systems in Ethiopia. Journal of Agriculture and Rural Development in the Tropics and Subtropics 117, 73-85.

Wurzinger M, Sölkner J and Iñiguez L 2011. Important aspects and limitations in considering community-based breeding programs for low-input smallholder livestock systems. Small Ruminant Research 98, 170-175. 